\title{
MAXILLOFACIAL RADIOGRAPHS
}

\author{
D W Hodgkinson, R E Lloyd, P A Driscoll, D A Nicholson
}

When the patient has a suspected cervical injury taking facial views can be dangerous because of the positioning that is required
This article deals with the problems facing non-specialist doctors requesting emergency radiographs of facial bones. An appropriate history and clinical examination will lead to suspicion of maxillofacial trauma and other pathology. We describe a systematic approach to requesting and interpreting maxillofacial views.

\section{Important anatomy}

The radiological anatomy of the face revolves around the air space
Knowledge of the normal anatomy and radiological appearance of the skull is essential to interpreting radiographs of the face (see article on skull, 4 December, pp 1476-81).

The face can be divided into three areas: the upper third-area above the superior orbital margin; the middle third-area between the superior orbital margin above and the occlusal plane below; and the lower third-the lower jaw (mandible). Standard radiographic investigation of the face is described with reference to these three areas.
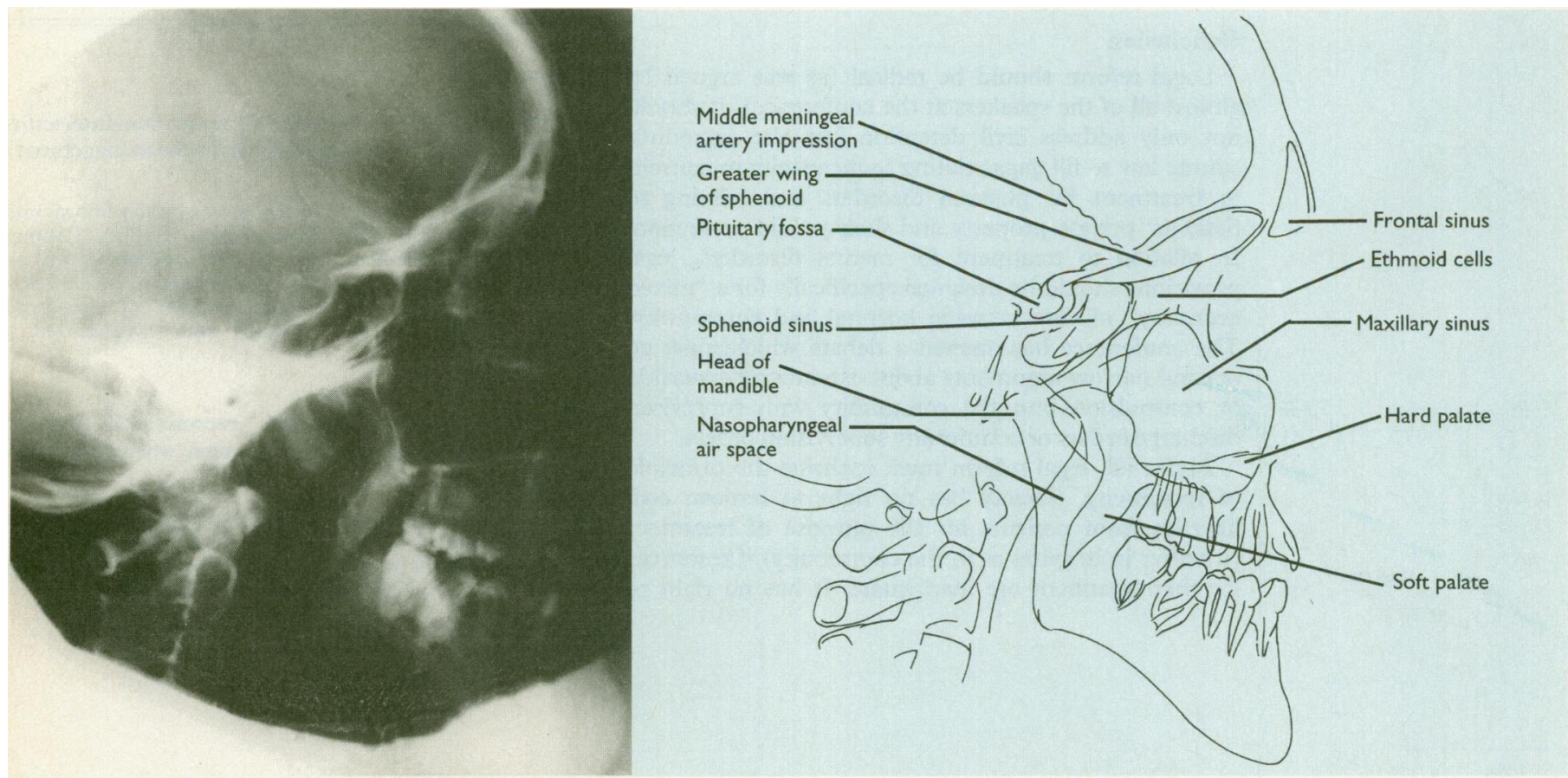

FIG 1-Lateral radiograph with line drawing showing radiological anatomy. 

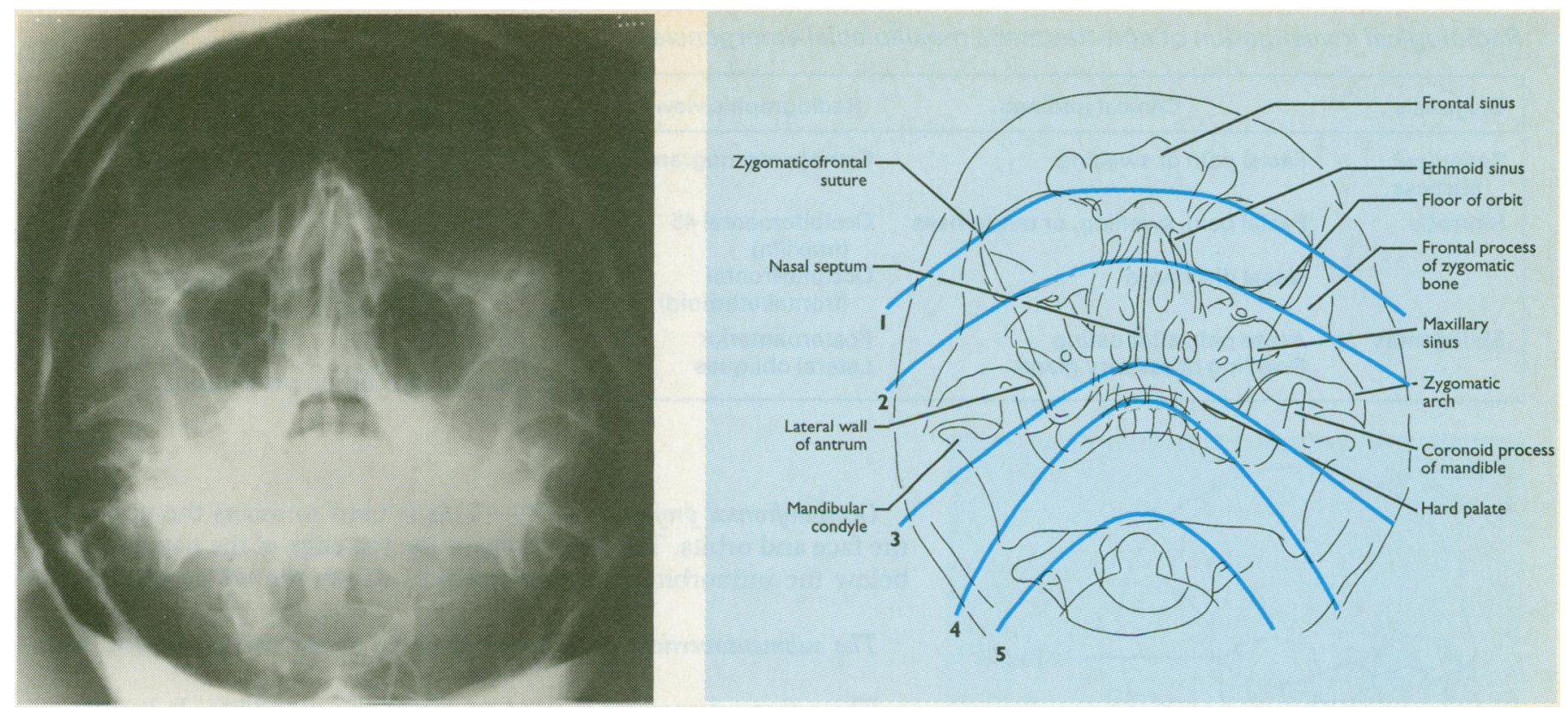

FIG 2-Occipitomental 45 radiograph with line drawing. The drawing also shows the five lines that should be traced when assessing the radiograph.

\section{Mechanism of injury}

In practice many injuries do not fit into the standard pattern of LeFort fractures. The classification is, however, still in general use for descriptive purposes
The mechanism of injury is an important aid to identifying the specific injury and any possible associated injuries. It can help decide which type of film to request and the urgency of the request. Isolated injuries to the maxillofacial skeleton commonly result from an assault. More' severe injuries occur after high energy transfer (for example, road traffic accidents) and may be associated with injuries to the head, neck, chest, and other body regions.

\section{Radiographic projections}

\section{Appropriate radiographic views for detecting trauma to maxillofacial regions}

\begin{tabular}{|c|c|c|}
\hline Anatomical site & Clinical findings & Radiographic view \\
\hline $\begin{array}{l}\text { Upper third: } \\
\text { Nasoethmoid }\end{array}$ & $\begin{array}{l}\text { Periorbital haematoma, epistaxis, } \\
\text { displaced nasal bones, deviated } \\
\text { nasal septum, cerebrospinal fluid } \\
\text { rhinorrhoea, transverse cleft in } \\
\text { glabellar region }\end{array}$ & $\begin{array}{l}\text { Occipitofrontal } \\
\text { and lateral }\end{array}$ \\
\hline Orbits & $\begin{array}{l}\text { Diplopia, enophthalmos, proptosis, } \\
\text { restriction of ocular movements }\end{array}$ & $\begin{array}{l}\text { Occipitofrontal } \\
\text { and lateral }\end{array}$ \\
\hline $\begin{array}{l}\text { Middle third: } \\
\text { Zygomatic } \\
\text { complex }\end{array}$ & $\begin{array}{l}\text { Periorbital oedema, haematoma, } \\
\text { infraorbital anaesthesia, step } \\
\text { deformities/flattening of the cheek }\end{array}$ & Occipitomental 45 \\
\hline $\begin{array}{l}\text { Zygomatic } \\
\text { arch }\end{array}$ & $\begin{array}{l}\text { Depression over arch, restriction } \\
\text { of mandibular movement }\end{array}$ & Submentovertical \\
\hline Maxilla & & Occipitomental \\
\hline LeFort 1 & $\begin{array}{l}\text { Swelling of upper lip and cheek, } \\
\text { mobile maxilla, teeth gagged } \\
\text { posteriorly }\end{array}$ & $\begin{array}{l}\text { Occipitomental } \\
\text { and lateral }\end{array}$ \\
\hline LeFort 2 and 3 & $\begin{array}{l}\text { Facial oedema (severe in 3), } \\
\text { periorbital haematoma, elongation of } \\
\text { face (dished), mobile maxilla, teeth } \\
\text { gagged posteriorly }\end{array}$ & $\begin{array}{l}\text { Occipitomental } 45 \\
\text { and lateral }\end{array}$ \\
\hline $\begin{array}{l}\text { Lower third: } \\
\text { Mandible }\end{array}$ & $\begin{array}{l}\text { Tenderness; bruising, swelling; } \\
\text { bleeding from mouth or ear, or } \\
\text { both; anaesthesia of lower lip; } \\
\text { crepitus or mobile fracture; } \\
\text { malocclusion or inability to } \\
\text { close the teeth }\end{array}$ & $\begin{array}{l}\text { Orthopantomogram } \\
\text { and posteroanterior } \\
\text { or Towne's, lateral } \\
\text { oblique, and } \\
\text { posteroanterior }\end{array}$ \\
\hline
\end{tabular}

Good quality, carefully positioned radiographs are required. This can be difficult to achieve in patients presenting to the emergency department (because of multiple injuries or alcohol intoxication). Poor quality and incorrectly positioned films must not be accepted. Radiology of a clinically suspected maxillofacial injury can often be delayed until the patient is more cooperative or good quality films can be taken.

The standard radiographic projections are listed below. Each projection provides only a limited amount of information and several views are therefore required to assess an injury fully. The clinical findings should be used to determine the probable site of injury and dictate which views are most appropriate. 


\begin{tabular}{|lll|}
\hline Diagnosis & \multicolumn{1}{c}{ Clinical findings } & Radiographic view \\
\hline $\begin{array}{c}\text { Periapical } \\
\text { abscess } \\
\text { Sinusitis }\end{array}$ & Facial pain or swelling & Orthopantomogram \\
& Facial pain, swelling, or tenderness & $\begin{array}{l}\text { Occipitomental 45 } \\
\text { (maxilla) } \\
\text { Occipitofrontal } \\
\text { (frontal/ethmoid) }\end{array}$ \\
Sialadenitis & $\begin{array}{l}\text { Acute pain after eating } \\
\text { Swelling of salivary gland }\end{array}$ & $\begin{array}{l}\text { Posteroanterior } \\
\text { Lateral obliques }\end{array}$ \\
\hline
\end{tabular}

Occipitomental projection $\left(45^{\circ}\right.$ and $\left.30^{\circ}\right)$-These views are used to assess the maxilla (LeFort 1, 2, and 3 fractures), the zygomatic complex, and orbital floor (fig 2).

The lateral projection (fig 1) is used to assess all three parts of the face. It can be taken with the patient lying supine on the table with a portable unit (unlike the other projections).

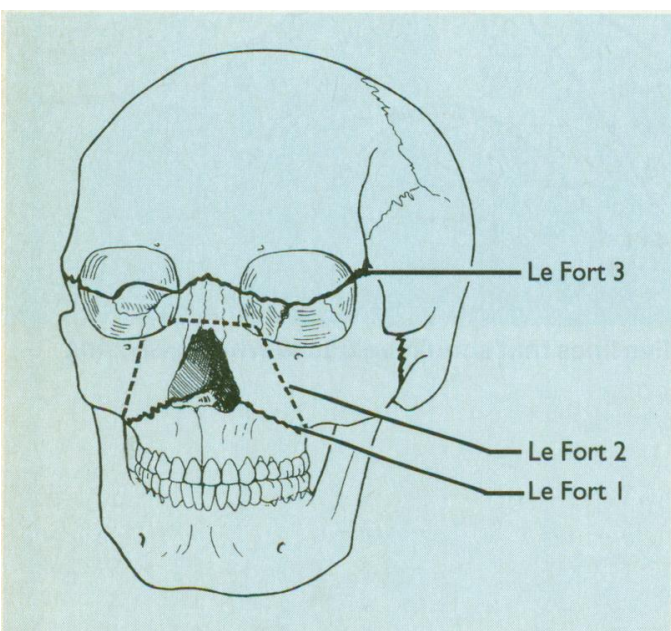

FIG 3-LeFort lines used for classifying fractures of the middle third of the face.

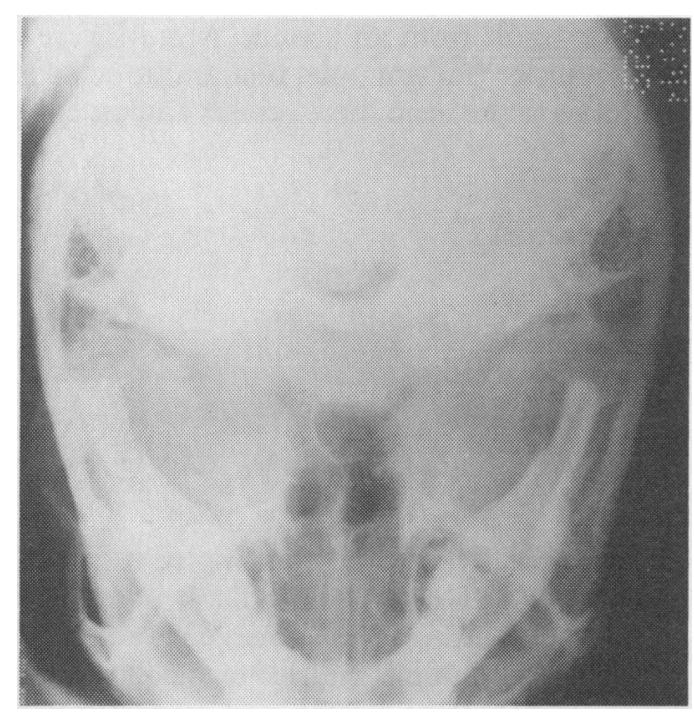

FIG 4-Submentovertical view showing a fractured zygomatic arch.
Occipitofrontal projection (25 )-This is used to assess the upper third of the face and orbits. The view projects the top edge of the petrous bones just below the infraorbital margins and thus shows the whole of the orbits.

The submentovertical projection is used to assess the zygomatic arch.

The orthopantomogram is used to assess the mandible. It is very informative but requires the cooperation of the patient because of the long exposure time. It is replacing the lateral oblique view as the best method of assessment.

\section{Posteroanterior projection $\left(10^{\circ}\right)$-This is used to assess the mandible.}

Towne's view shows the ascending rami of the mandible and the condyles on each side.

Lateral oblique projection-These views are valuable for assessing the body of the mandible.

\section{Nasal bones}

A simple nasal bone fracture is diagnosed clinically and routine radiography of the nasal bones is unnecessary. Trauma to the bridge of the nose may produce a nasoethmoid fracture. These patients usually have persistent epistaxis or cerebrospinal fluid rhinorrhoea, or both. This injury cannot be excluded by plain radiographs.

\section{Temporomandibular joint projection}

These specialised views should be requested only when specific information about the function of the joint is required. Non-specialists should not need to request or interpret these views. Fractures of the mandibular condyle are common and are diagnosed with other views. They rarely affect the temporomandibular joint except when the condyle and the glenoid fossa are fractured together in high energy trauma.
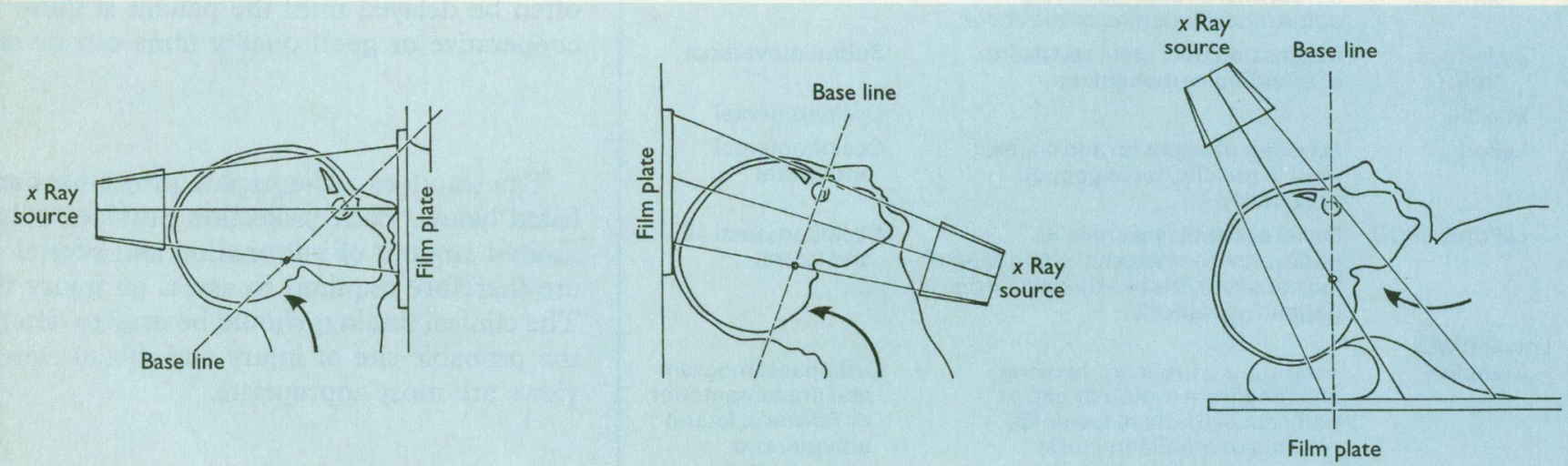

FIG 5-The positioning of the patient, the $x$ ray source, and the film for (from left to right) the occipitomental 45 , submentovertical, and Towne's views. The base line is the line drawn between the external auditory meatus and the orbit. 


\section{Radiological assessment of occipitomental view}

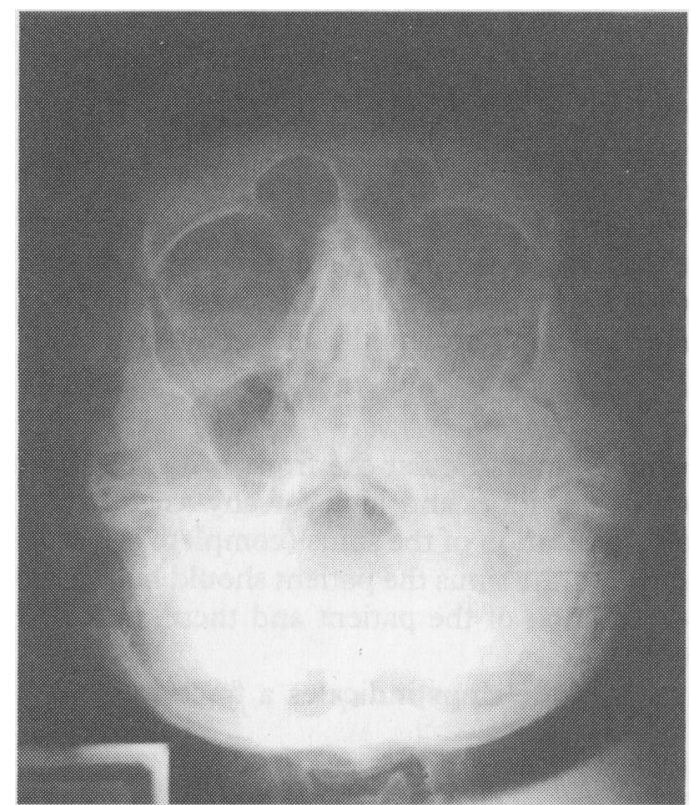

FIG 6-Occipitomental view showing fractured zygoma. Note the increased size of the left orbit and opacification of the left maxillary sinus.

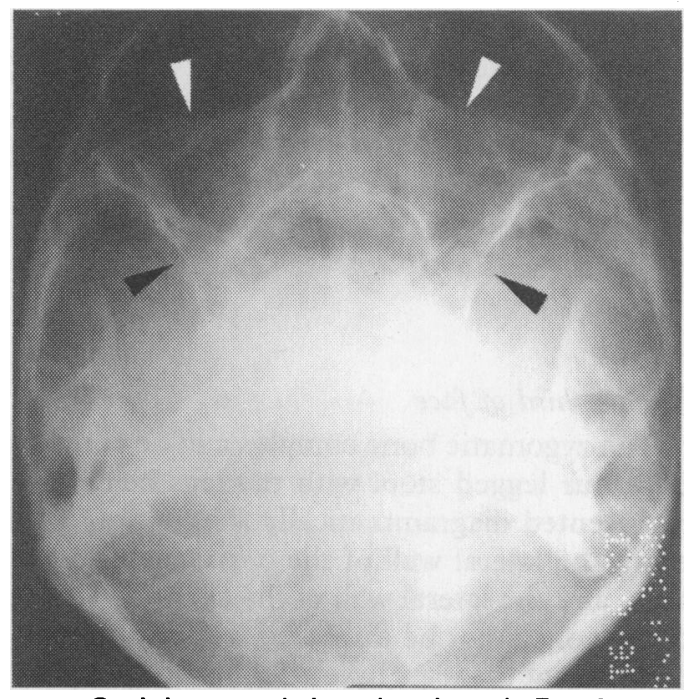

FIG 7-Occipitomental view showing a LeFort 2 fracture. Fractures are visible on both sides (arrows). The opacification of both maxillary sinuses and the general hazy appearance of the film is consistent with severe soft tissue swelling.
Radiographs should be interpreted by using the ABCs system.

\section{Adequacy and quality of the radiograph}

Start by identifying the name of the patient and the date on which the radiograph was taken. Then ensure that it is correctly centred by tracing a line that connects the nasal septum, the centre of the mandible, and the odontoid peg. This should be vertical, straight, and run through the centre of the film. Next look for rotation by tracing the outline of the orbits; they should be the same size and shape and the lateral walls should be of equal thickness and equidistant from the nasal septum. Another method of assessing rotation is to draw the imaginary Campbell line 2 (see below) and look for rotation of the orbits about a vertical and horizontal axis.

\section{Alignment and bones}

Figure 2 shows the five lines that should be traced when assessing the radiograph. They are known as Campbell's lines.

Line 1 joins the two zygomaticofrontal sutures. It runs along the superior orbital margin on each side and centrally across the region of the glabella. Check for any separation of the zygomaticofrontal suture and look at the integrity of the superior orbital margins.

Line 2 is traced from the zygomatic arch. It follows the zygomatic bone and continues along the inferior orbital margin across the frontal process of the maxilla and lateral wall of the nose through the septum. It then follows a similar course on the other side. Check the zygomatic arch for fractures then compare the transverse width of the frontal process of the maxilla and vertical dimensions of the zygomatic bones on the left and right side. Any asymmetry may indicate a fracture. Look for a break in continuity of the inferior orbital margin, particularly at the junction of the inner third and outer two thirds. A downward blow out fracture of the orbit may be seen (tear drop sign), but this is not a consistent feature in this injury.

Line 3 starts at the condyle of the mandible and traces across the mandibular notch and coronoid process to the lateral wall of the maxillary antrum. It continues through the medial wall of the antrum or lateral wall of the nose at the level of the nasal floor and then follows a similar course on the opposite side. Check the continuity of the maxillary antral walls and look for any depression of the orbital floor.

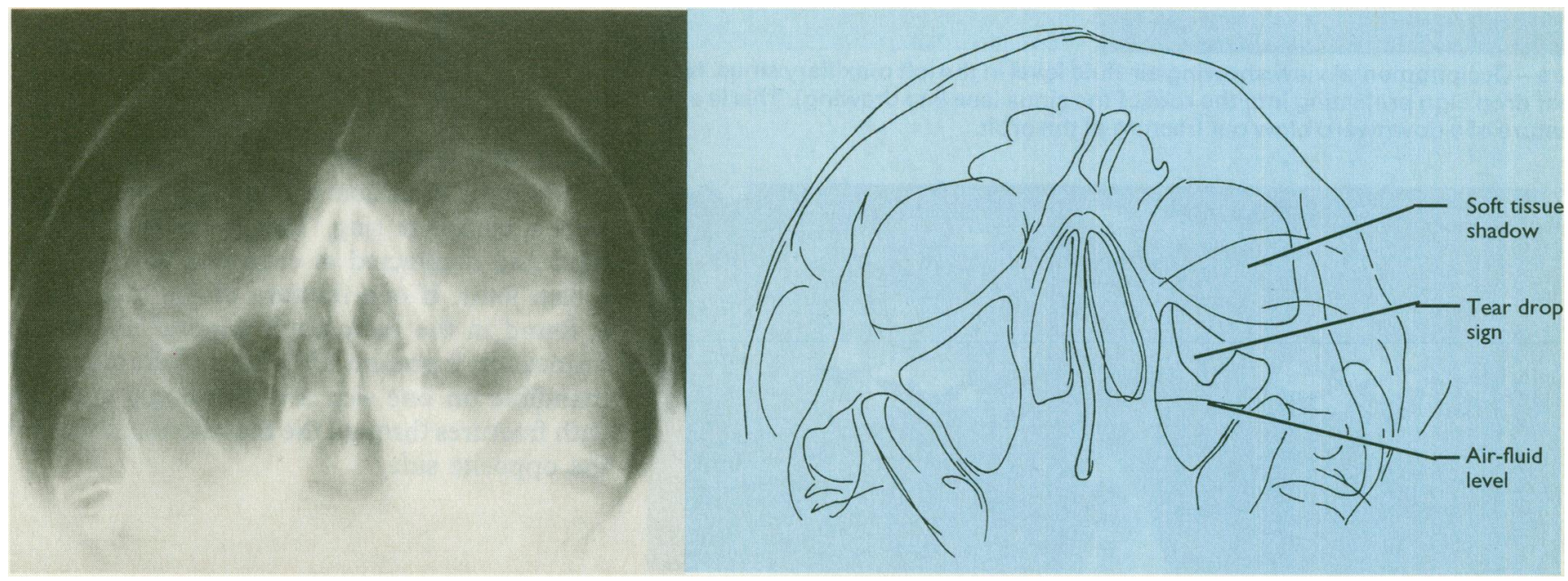

FIG 8-Occipitomental view showing a fractured zygomatic bone complex and line drawing showing disruption of all four legs of the stool (arrows). 
Any fluid level seen in a radiograph will depend on the orientation of the patient when the film was taken (erect or supine)

\section{Indirect signs of maxillary fracture}

\section{- Soft tissue swelling}

- Opacification of the maxillary sinus is usual in fractures which affect its wall and an air-fluid level is usually seen

- Soft tissue emphysema is a rare but useful sign. It provides positive evidence of a fracture of the nasal cavity or one of the paranasal sinuses. It may show as multiple small radiolucent areas in the soft tissues. Alternatively air may enter the orbit to outline the eyeball
Line 4 follows the occlusal curve of the upper and lower teeth. Check for evidence of mandibular fractures, although the definition may be poor and specific views are required for detailed assessment.

Line 5 traces the line of the lower border of the mandible. Check the continuity of this line.

\section{Cartilages and joints}

Look at the separation of the zygomaticofrontal suture located on line 1 above. Look for asymmetry between the two sides. The joint space should be smooth and thin, symmetrical along its length, and uninterrupted.

\section{Sinuses}

Check all the paranasal sinuses, in particular the frontal, maxillary, and ethmoid. Trace the outline of each sinus and look for any asymmetry between each side. Look for opacification of the sinus (complete or partial).

If a fluid level is suspected within the sinus the patient should have a brow up lateral projection. The orientation of the patient and therefore the airfluid level will differ in the two views.

Discontinuity in the margins of the sinus indicates a fracture.

\section{Soft tissue}

Check the soft tissues by using a bright light. The soft tissue shadow from the line of the cheek can be seen traversing the orbit. If excessive swelling is present on one side the maxillary antrum on the same side may appear more radio-opaque. Look for a tear drop appearance in the top of the maxillary antrum. This may represent a blow out fracture of the orbital floor in the correct clinical context.

Check for foreign bodies within the soft tissues. Some objects (for example, glass) can be difficult to see without a bright light.

\section{Important rules and diagnostic traps}

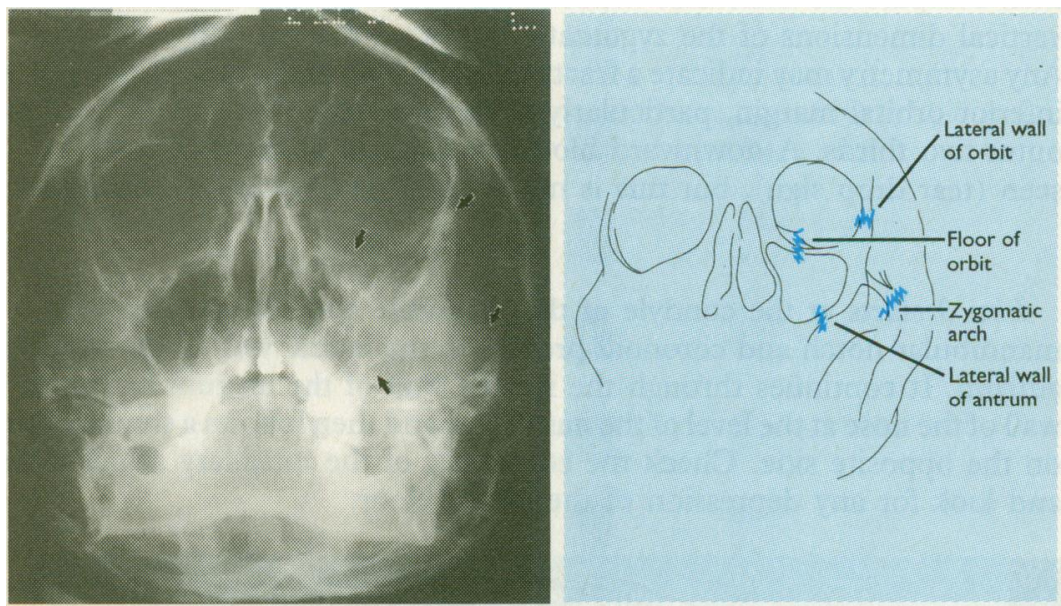

FIG 9-Occipitomental view showing air-fluid level in the left maxillary sinus. Note tear drop sign projecting into the roof of the sinus (see line drawing). This is a feature of a downward blow out fracture of the orbit.

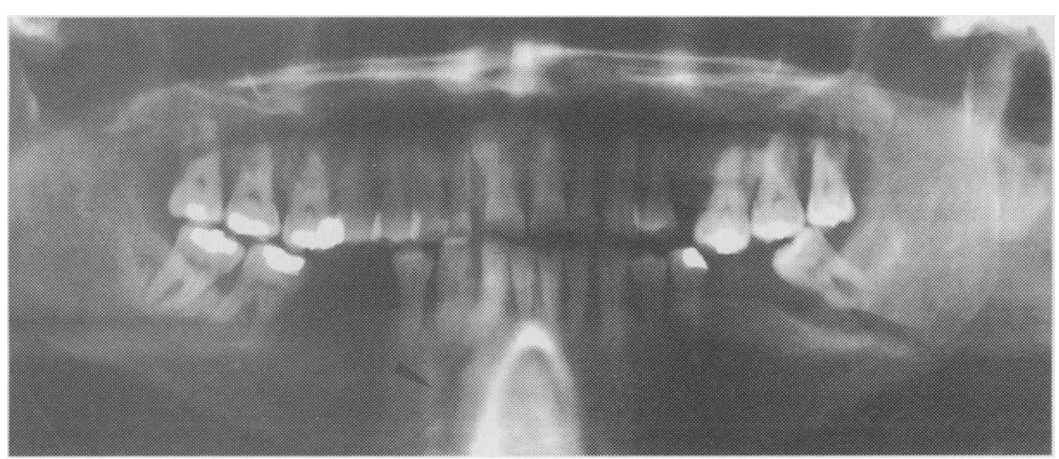

FIG 10-Orthopantomogram showing fracture through the angle of the mandible on the left side and a subtle fracture through the body on the right side (arrow).

\section{Middle third of face}

The zygomatic bone complex can be compared to a four legged stool with the legs being represented diagrammatically as: the floor of the orbit, the lateral wall of the orbit, the zygomatic arch, and the lateral wall of the antrum. The seat of a stool cannot be displaced without moving at least two of the legs. Likewise it is not possible to displace the zygomatic bone without fracturing two of the legs. Thus if one leg is thought to be fractured the other three must be checked.

\section{Lower third of the face}

When the mandible is injured it behaves as if it were a complete ring. This is because it is rigid and connected at each end of the skull by a firm joint. If one fracture of the mandible is found in the radiograph another fracture or dislocation is present. Fractures of the angle of the mandible on one side are commonly associated with fractures through the mandibular condyle on the opposite side. 


\begin{tabular}{|l|}
\hline Summary \\
Adequacy \\
Alignment \\
Check lines 1-5 \\
Bones \\
Cartilage and joints \\
Zygomaticofrontal suture \\
Sinuses \\
Opacification \\
Air-fluid levels \\
Soft tissue \\
Swelling \\
Foreign bodies
\end{tabular}
This is the sixth in a series
articles describing current techniques in minimal access surgery. The articles have been written to inform nonspecialists of developments in this rapidly moving subject.

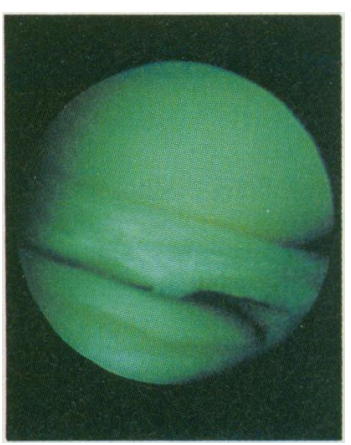

FIG 1-Torn medial meniscus in knee joint

\begin{abstract}
Addenbrooke's Hospital, Cambridge CB2 2 QQ Richard N Villar, consultant orthopaedic surgeon
\end{abstract}

$B M \mp 1994 ; 308: 51-3$

\section{Arthroscopy}

\author{
Richard N Villar
}

Normal anatomical structures can sometimes be mistaken for fractures. There are four common sites:

- Air in the oropharynx at the. angle of the mandible. If checked carefully this line will extend beyond the outer cortex of the mandible

- Calcification or ossification of the stylohyoid ligament projecting over or just behind the ascending ramus

- The hyoid bone shown over the posterior part of the horizontal ramus - The intervertebral spaces of the upper cervical vertebrae overlying the maxillae, simulating a LeFort 1 fracture, or over the mandibular symphysis, mimicking a dentoalveolar fracture.

Fractures of the mandible, particularly at the angle and the condyle, can appear undisplaced when seen in only one view. At least two views at right angles to each other are essential for full assessment-posteroanterior, Towne's, or lateral oblique.

The anterior mandible can be difficult to see in the orthopantomogram and lateral oblique projection because of superimposition of other structures. A lower occlusal view of the anterior mandible may therefore be useful in certain situations.

D W Hodgkinson is lecturer in emergency medicine, R E Lloyd is consultant maxillofacial surgeon, P A Driscoll is senior lecturer in emergency medicine, and D A Nicholson is consultant radiologist, Hope Hospital, Salford.

The line drawings were prepared by Mary Harrison, medical illustrator.

The ABC of Emergency Radiology has been edited by David Nicholson and Peter Driscoll.

\section{Minimally Invasive Surgery}

Arthroscopy has reduced the morbidity and period of hospitalisation associated with orthopaedic surgery and has increased the range of procedures that may be performed. From early operations on the knee it has expanded to include procedures for the shoulder, elbow, wrist, hip, ankle, and foot. For some joints the indications for surgery are clear, for others the clinical advantages are still being assessed. This expansion has also led to the recognition of complications, though the incidence is low. Specialist instrumentation has allowed a wide variety of operations previously needing open surgery to be carried out arthroscopically. The repertoire of arthroscopic procedures will undoubtedly continue to expand, and controlled studies are required to validate their efficacy, particularly in the management of degenerative joint diseases.

Arthroscopy has revolutionised orthopaedic surgery: combining diagnostic accuracy, low morbidity, and short length of hospitalisation, it is now one of the commonest orthopaedic procedures performed. As with all innovations, however, arthroscopy has had sceptics, and in 1937 Hustinx said of arthroscopy of the knee: "How can anyone venture to introduce a luminous object into the knee-joint in an effort to look between the articular surfaces, which cannot be separated...? This is quite impossible. Moreover, this procedure is more dangerous than exploratory arthrotomy."

The development of a rod lens system (designed by Professor Hopkins) surrounded by light conducting glass fibrils and enclosed in a rigid metal sheath led to the modern arthroscope. It soon became apparent that this versatile instrument had numerous applications. It was initially used for diagnostic purposes only, but instrumentation was developed to allow treatment of pathology as well. By the late 1970s arthroscopic operations had become established in the developed world. Early operations were mainly performed on the knee. Being mobile and easily accessible, it is particularly suitable for arthroscopy. Much was learnt about its anatomy and the natural history of knee conditions.

Orthopaedic surgeons and their patients soon appreciated the advantages of such keyhole surgery on the knee, and other joints were investigated. Burman had paved the way for this in 1931 by looking at many different joints in cadavers. ${ }^{2}$ Arthroscopy may now be performed in many joints including the shoulder, elbow, wrist, ankle, hip, and even the first metatarsophalangeal joint.

\section{Knee arthroscopy}

The knee is still the most frequently arthroscoped joint, although the advent of magnetic resonance imaging has reduced the need for diagnostic knee arthroscopy. Much recent research has been performed to relate the findings of magnetic resonance imaging to those of arthroscopy ${ }^{3}$ : in general, a negative scan is probably correct but a positive scan may not be. Arthroscopy should only be performed, however, if the symptoms suggest it.

Though the need for diagnostic knee arthroscopy recedes, the range of operative procedures available increases. It is now possible to perform arthroscopic reconstruction of the anterior cruciate ligament, meniscal repair, fixation of a tibial plateau fracture, and assessment of a painful total knee replacement as well as more established techniques such as meniscectomy (fig 1), synovectomy, and retrieval of loose bodies. 